\title{
Modificaciones en los estatutos y reglamentos de la Sociedad Chilena de Enfermedades Respiratorias
}

\author{
Modifications of ordinances and by-laws of the Chilean Respiratory Disease Society
}

La actual Sociedad Chilena de Enfermedades Respiratorias, continuadora de la Sociedad Chilena de Tisiología creada el 13 de Marzo de 1930, ha tenido desde su creación los Estatutos y Reglamentos que permiten y ordenan su funcionamiento de acuerdo a los diferentes tiempos, usos y costumbres de cada época ${ }^{1}$.

La creciente importancia que la especialidad ha tenido, pasando de la Tuberculosis a las diferentes y cada vez más complejas patologías respiratorias, con el sostenido ingreso de nuevos especialistas y la constitución oficial como sub-especialidad de la Medicina Interna ${ }^{1,2}$, ha obligado a nuestra Sociedad a una progresiva adecuación de sus normativas, para hacerlas más eficientes y así tener una mejor respuesta a los desafios administrativos, societarios y cientificos.

En los últimos años un cambio mayor de los Estatutos se produjo en 1996, bajo la presidencia de la Dra. Patricia Díaz A., con el objetivo de lograr una mejor continuidad en el manejo de la Sociedad y sus bienes, a través de la capacitación en las labores directivas del futuro Presidente, quien primero debe ejercer por dos años el cargo de Vicepresidente. Este cargo, elegido por votación directa de los socios, tiene por finalidad que la persona elegida paulatinamente vaya asumiendo mayores responsabilidades para que al terminar el período de la Directiva pase a integrar el siguiente período como Presidente, con todas las atribuciones y la experiencia que este cargo requiere. Desde su creación se ha demostrado que dicho acuerdo ha sido beneficioso para la continuidad societaria.

Este cambio de los Estatutos trajo también el desempeño conjunto de un abogado para la redacción de ellos, lo que ha continuado hasta la actualidad, permitiendo así conocer y mantener el espiritu que ha animado a nuestra Sociedad desde su fundación. El Sr. Yerko Koscina P. nos ha entregado su experiencia en este tema y ha sido consultor de las inquietudes legales de las diferentes Directivas, permitiendo además al autor de estas líneas tener un creciente manejo en estos complicados instrumentos legales.

Después de la legalización oficial de los nuevos Estatutos se realizó el trabajo de reformar los Reglamentos, proceso largo pues lleva a la práctica diaria y en forma más detallada lo que señalan los diferentes artículos de los Estatutos. Se pudo plasmar asi el funcionamiento de Filiales, Ramas, Comisiones y de la Directiva, permitiendo el crecimiento armónico y regulado de la Sociedad. Dichos Reglamentos fueron sistematizados y entregados oficialmente en el año 2000, bajo la presidencia del Dr. Rodrigo Gil D. y se han constituido en necesaria referencia para los nuevos Directores.

Como en toda estructura viva, los cambios tecnológicos también provocaron necesidades de crecimiento y de nuevos instrumentos para la Sociedad. La informática y la red mundial de Internet nos han llevado a la creación de una página Web oficial, con la consabida abreviación de nuestro nombre a "SER Chile" (www.serchile.cl), página de gran importancia no solo para los socios sino también para la creciente inquietud de otros profesionales y del público general.

Es así como para aprovechar ésta y otras formas de comunicación, en el año 2007 y bajo la presidencia del Dr. Raúl Corrales V. se realizó otra reforma de Estatutos para permitir que las elecciones se puedan realizar por correo certificado o por vía electrónica e Internet, permitiendo así el sufragio de quienes no concurren a la Asamblea Ordinaria para votar en forma presencial y así aumentar la base electoral de la Directiva ${ }^{3}$. En las dos últimas elecciones este sistema no presencial ha significado un aporte sustancial en mayor cantidad de votantes. Aprovechando el esfuerzo de la Asamblea Extraordi- 
naria citada para esta modificación, se agregó la posibilidad de hacer las reuniones de Directorio con modalidad de comunicación vía conferencia en red.

La complejidad que el actual desarrollo de la Sociedad impone a nuestra Directiva hizo aparecer situaciones de dificil manejo, que hicieron pensar a los Directores en la necesidad de clarificar y manejar reglamentariamente aspectos como ausencias prolongadas o actuaciones fuera de contexto, que no estaban contempladas en la reglamentación vigente y que tampoco ameritaban la expulsión como socio, drástica sanción mayor y única presente en los Estatutos.

Es así como el año 2009 recién pasado y bajo la presidencia del Dr. Fernando Rivas B. se llamó a Asamblea Extraordinaria para modificar el artículo 34 de los Estatutos y detallar lo que se considera ausencia reiteradas no justificadas y para crear la censura a uno o más miembros del Directorio cuando su accionar no se ajusta a lo señalado en nuestra normativa 4 . Esta modificación, a diferencia de las anteriores, no contempló un artículo transitorio que la hiciese efectiva de inmediato, por lo cual sólo se puede aplicar a partir de la Directiva recientemente electa para el bienio 2010-11. Si la censura es aprobada, el miembro del Directorio es removido de su cargo y su reemplazo se realiza utilizando los mecanismos señalados anteriormente para los casos de renuncia o incapacidad por enfermedad prolongada.

Las modificaciones a los Estatutos de 2007 y 2009 obligaron a redactar un nuevo texto refundido y sistematizado de los Reglamentos, que incorporara las modificaciones necesarias para la aplicación de las reformas y que constituyera la nueva referencia de nuestro marco organizacional. Ellos fueron aprobados en la Asamblea Ordinaria recién pasada y esperamos que su presencia en la página web de la Sociedad (www.serchile.cl) sea de utilidad para todos los socios.

Finalmente, podemos decir que nuestra Sociedad cuenta con Estatutos y Reglamentos que reflejan no solo el espíritu que ha animado a nuestros fundadores y las generaciones que los siguieron, sino además son lo suficientemente adecuados y flexibles para permitir el trabajo de los distintos actores que componen nuestro marco humano y profesional, llevándonos a la vanguardia en este tema, no solo en el ámbito nacional.

Dr. Juan Céspedes Galleguillos Coordinador, Comisión de Estatutos y Reglamentos Sociedad Chilena de Enfermedades Respiratorias

\section{Bibliografía}

1.- MENA G. El tránsito desde la Tisiología a la especialidad actual en Chile. Enferm Respir Cir Torác 1989; 5: 99-108.

2.- BARROS M. Sociedad Chilena de Enfermedades Respiratorias: 75 años de historia. Rev Chil Enf Respir 2005; 21: $5-7$.
3.- CRUZ E, VALDIVIA G. Panorama: Modificación de estatutos de la Sociedad. Rev Chil Enf Respir 2007; 23 : 217-8.

4.- RIVAS F, SCHÖNFFELDT P. Cuenta del directorio de la Sociedad Chilena de Enfermedades Respiratorias 2009; 25: 286-91. 